\title{
Friction and mixing effects on potential vorticity for bottom current crossing a marine strait: an application to the Sicily Channel (central Mediterranean Sea)
}

\author{
F. Falcini and E. Salusti \\ CNR-ISAC, Via del Fosso del Cavaliere 100, 00133 Rome, Italy \\ Correspondence to: F. Falcini (f.falcini@isac.cnr.it) \\ Received: 8 August 2014 - Published in Ocean Sci. Discuss.: 18 November 2014 \\ Revised: 25 March 2015 - Accepted: 22 April 2015 - Published: 21 May 2015
}

\begin{abstract}
We discuss here the evolution of vorticity and potential vorticity (PV) for a bottom current crossing a marine channel in shallow-water approximation, focusing on the effect of friction and mixing. The purpose of this research is indeed to investigate the role of friction and vertical entrainment on vorticity and PV spatial evolution in channels or straits when along-channel morphology variations are significant. To pursue this investigation, we pose the vorticity and PV equations for a homogeneous bottom water vein and we calculate these two quantities as an integral form. Our theoretical findings are considered in the context of in situ hydrographic data related to the Eastern Mediterranean Deep Water (EMDW), i.e., a dense, bottom water vein that flows northwestward, along the Sicily Channel (Mediterranean Sea). Indeed, the narrow sill of this channel implies that friction and entrainment need to be considered. Small tidal effects in the Sicily Channel allow for a steady theoretical approach.

We argue that bottom current vorticity is prone to significant sign changes and oscillations due to topographic effects when, in particular, the current flows over the sill of a channel. These vorticity variations are, however, modulated by frictional effects due to seafloor roughness and morphology. Such behavior is also reflected in the PV spatial evolution, which shows an abrupt peak around the sill region. Our diagnoses on vorticity and PV allow us to obtain general insights about the effect of mixing and friction on the pathway and internal structure of bottom-trapped currents flowing through channels and straits, and to discuss spatial variability of the frictional coefficient. Our approach significantly differs from other PV-constant approaches previously used in studying the dynamics of bottom currents flowing through rotating channels.
\end{abstract}

\section{Introduction}

An ongoing debate in diagnostic models for currents that flow over a sill in a rotating channel with varying cross sections concerns the effect of friction and mixing, which clearly plays an important role in the presence of morphological constraints (Pratt et al., 2008; Pratt and Whitehead, 2008). Despite such a role, these two key effects are often not considered in the literature. Idealized models for marine currents flowing through rotating channels (e.g., Whitehead et al., 1974; Gill, 1977; Borenas and Lundberg, 1986, 1988; Killworth, 1992) usually assume a steady state and are often simplified, out of necessity, for a feasible analytic investigation (Pratt and Whitehead, 2008). This, for instance, leads to friction being neglected, assuming a uniform potential vorticity (PV) and considering channels with rectangular or smooth, idealized cross sections in order to avoid dynamic pathologies at the current lateral edges (Lacombe and Richez, 1982; Hogg,1983; Pratt et al., 2008).

In particular, the most often cited models for these currents assume a zero-PV flow (Whitehead et al., 1974; Borenas and Lundberg, 1988). Such an assumption is mostly applied for fluid columns coming from a quasi-quiescent upstream state and then severely squashed as they cross the sill of a channel. Along-channel profiles of depth and velocity of these approximated currents are particularly simple to predict and, for the case of a rectangular cross section, it has been demonstrated that such flows are also stable (Paldor, 1983). In fact, realistic bottom marine currents that are confined to channels or straits show a thickness that goes to zero at the lateral edges, which can lead to pathological features in terms of flow stability (Pratt et al., 2008). 
A second, often adopted approximation is given by disregarding friction and vertical entrainment of bottom currents flowing in rotating channels (Armi and Farmer, 1985; Bryden and Kinder, 1991; Whitehead et al., 1974; Gill, 1977; Borenas and Lundberg, 1986). Friction and entrainment in fact play an important role for currents crossing channels or straits (Johnson and Ohlsen, 1994), in particular when along-channel morphology variations are present (Borenas and Lundberg, 1986, 1988; Killworth, 1992, among others). Experimental data have shown complicated dynamics that suggest a strong effect of both interfacial and bottom friction that may induce a secondary circulation (Johnson et al., 1976).

These considerations are at the base of our interest for a more realistic analysis of bottom currents that cross a narrow marine channel, in the presence of an irregular morphology, and flow underneath upper layers that have different dynamics. We do not aim to provide a prognostic model to be tested with observations, but rather to introduce the potential effect of bottom friction and entrainment effects in integral forms of vorticity and PV. To pursue such an investigation, we derive vorticity and PV equations from the classic stream-tube model (Smith, 1975; Killworth, 1977), which describes the steady properties of a homogeneous, viscous bottom water vein, also considering entrainment in the mass conservation equation (Turner, 1986). We then discuss these equations in order to figure out the role of seafloor morphology, friction, and mixing in marine channel dynamics. We finally introduce the hydrographic settings of the Sicily Channel (Fig. 1) (Astraldi et al., 2001; A01 hereafter) and employ interpolated, cross-averaged flow velocity $(\bar{u})$ and thickness $(\bar{h})$ data related to the Eastern Mediterranean Deep Water (EMDW; a bottom vein flowing northwestward through the Sicily Channel) in order to diagnose our vorticity and PV equations. The EMDW flows underneath the Levantine Intermediate Water (LIW) and the Modified Atlantic Water (MAW). Those currents constitute a three-layer system (Fig. 2), whose hydrodynamics are strongly affected by baroclinic, mixing, and topographic effects (A01).

Our approach differs from a similar investigation proposed by Hogg (1983) and Whitehead (1998), among many others, who analyzed the hydraulic control and frictionless flow separation in the Vema Channel. The Sicily Channel has relatively unimportant tides; its sill is $300 \mathrm{~m}$ deep and shows an irregular and narrow morphology, all features that make this channel particularly suitable for our goals and theoretical approaches. In particular, the usual inviscid quasi-geostrophic approach does not seem particularly adequate in the Sicily Channel.
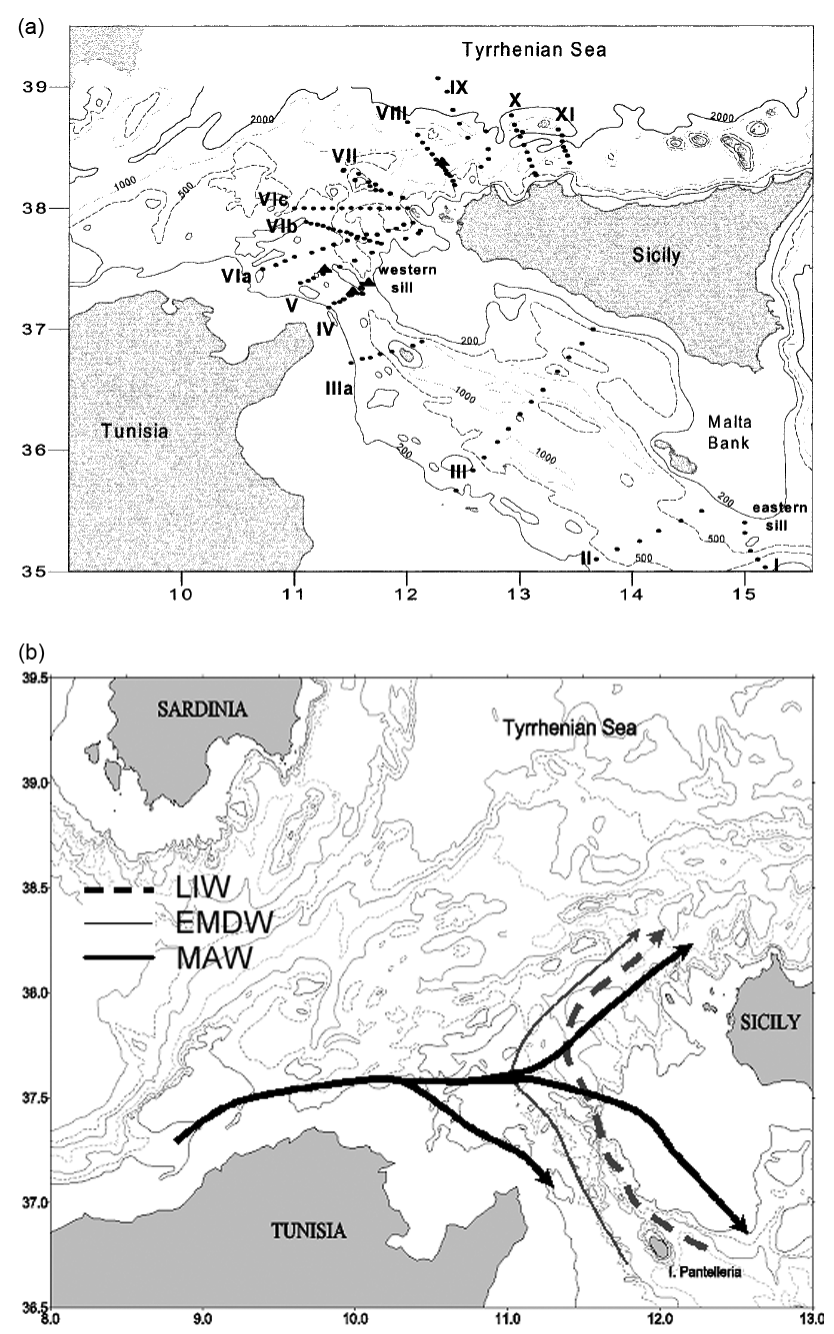

Figure 1. (a) General map of the Sicily Channel: the channel length is $\sim 500 \mathrm{~km}$, with two sills at its eastern and western entrances ( $\sim 550$ and $\sim 350 \mathrm{~m}$ deep, respectively). Dots indicate the hydrographic stations of all cross section vertical transects; triangles indicate the position of current-meter chains. The Ionian Sea is on the southeastern side of the map. From Astraldi et al. (2001). (b) Main routes of the principal water masses flowing through the region: LIW (Levantine Intermediate Water; dashed line), EMDW (Eastern Mediterranean Deep Water; solid line), and MAW (Modified Atlantic Water; bold line). The trajectory of the EMDW corresponds to the centerline of the vein in the different hydrographic sections. After Astraldi et al. (2001).

\section{Momentum and mass conservation of dense flows for realistic channels}

Here we consider the dynamics of a shallow, homogeneous bottom layer of fluid flowing in a deep channel underneath upper moving layers of water that have a slightly lower density. The channel is thought to be aligned along the $x$ direction and has a realistic, quasi-rounded cross section (Fig. 2a). The stream-wise evolution of such a bottom flow is governed 

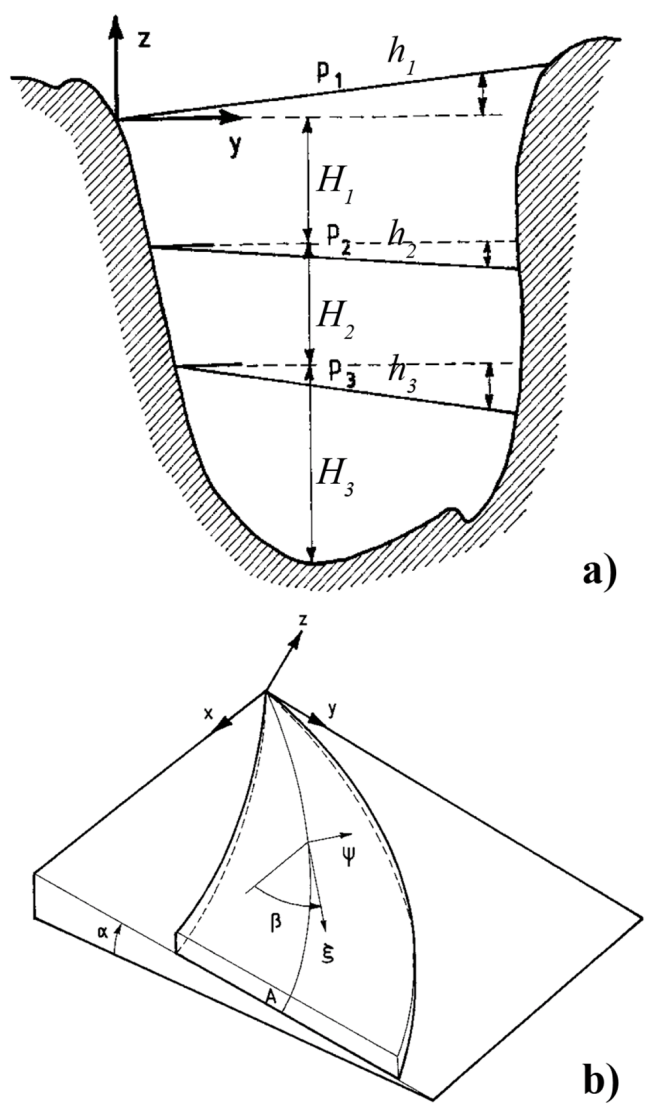

Figure 2. (a) Schematic representation of the three layers in a crossflow vertical transect. The interfaces are at $z=h_{1}$ for the air-sea surface, at $z=H_{1}+h_{2}$, and at $z=H_{1}+H_{2}+h_{3}$ for the lower interfaces, with $H_{1}=$ const and bottom depth $=H_{1}+H_{2}+H_{3}$. (b) Diagram of a bottom current also showing the $(x, y)$ and $(\xi, \psi)$ coordinate systems. Modified from Astraldi et al. (2001).

by the shallow-water equations. The use of the full equations, rather than "balance" equations or other approximations, is required in order for hydraulic effects to be accurately captured (Pratt et al., 2008).

To take into account the role of upper layers, we consider a shallow-water model for multiple homogeneous layers with thicknesses $h_{j}$, densities $\rho_{j}$, and velocities $\boldsymbol{u}_{j} \equiv\left(u_{j}, v_{j}\right)$, where $j=1,2,3$ indicates the different layers; $z$ is the vertical coordinate (positive upward); $t$ is the time; $b(x, y)$ is the sea bottom, with $\frac{\partial b}{\partial x} \ll \frac{\partial b}{\partial y}$; and $W_{j}(x)$ being the crosschannel layer widths (Fig. 2a).

The hydrostatic pressure related to the third layer $(j=3)$ can be written as (Hogg, 1983; A01)

$p_{3}=p_{0}^{\prime \prime}+g \rho_{3}\left(h_{3}-z\right)+g \rho_{2}\left(h_{2}-h_{3}\right)+g \rho_{1}\left(h_{1}-h_{2}\right)$,

where $p_{0}^{\prime \prime}$ is a constant and $g$ is the gravitational acceleration (Fig. 2a).

The full shallow-water equation for a streamline in the third layer is as follows (Gill, 1982, p. 231-232; Pratt et al.,
2008):

$$
\begin{aligned}
& \delta \frac{\partial}{\partial t} u_{3}+\delta u_{3} \frac{\partial}{\partial x} u_{3}+\delta v_{j} \frac{\partial}{\partial y} u_{3}-f v_{3} \\
& =-\frac{1}{\rho_{3}} \frac{\partial}{\partial x} p_{3}+\delta^{*} \frac{\boldsymbol{F}_{3}}{\rho_{3}}, \\
& \delta \frac{\partial}{\partial t} v_{3}+u_{3} \frac{\partial}{\partial x} v_{3}+v_{3} \frac{\partial}{\partial y} v_{3}+f u_{3} \\
& =-\frac{1}{\rho_{3}} \frac{\partial}{\partial y} p_{3}+\delta^{*} \frac{\boldsymbol{F}_{3}}{\rho_{3}}, \\
& \delta \frac{\partial}{\partial t} h_{3}+h_{3} \frac{\partial}{\partial x} u_{3}+h_{3} \frac{\partial}{\partial y} v_{3} \\
& =\delta^{*} E\left|u_{3}-u_{2}\right|,
\end{aligned}
$$

where $\delta$ and $\delta^{*}$ are Boolean functions; $f$ is the Coriolis parameter; $\boldsymbol{F}_{3}$ and $E\left|u_{3}-u_{2}\right|$ represent, respectively, friction and entrainment between adjacent layers; and $E$ is a suitable entrainment parameter. In Eq. (2), $\delta=0$ gives the steady, quasi-geostrophic approximation, while $\delta^{*}=0$ leads to the inviscid case. $\boldsymbol{F}_{3}$ contains both inter-layer friction and bottom stress, schematizing the upper and lower friction, which mainly occurs at the boundaries of the bottom layer. These stresses induce both upper and lower Ekman spirals, in addition to some entrainment effects (Johnson and Ohlsen, 1994). We point out that entrainment should also be included in the momentum budget (Eq. 2a and b). Since friction with the overlying layer is included, the momentum impact of entrainment (entrainment drag) has indeed a potential role. However, this results in being another term that is lumped into a residual and we therefore omit such a term.

A general formulation for bottom friction can be defined as (Baringer and Price, 1997a, b; A01)

$\boldsymbol{F}_{3}=-\rho_{3} X\left(\boldsymbol{u}_{3}, h_{3}\right) \boldsymbol{u}_{3}$,

where $X\left(\mathrm{~s}^{-1}\right)$ is, in general, an empirical, nonlinear relation. In the following we will use the formulation $X=K^{*} \frac{\rho \bar{u}}{\bar{h}}-$ with $K^{*}=$ constant - that takes account of the averaged flow thickness and velocity (A01).

Ekman transport effects induced between the intermediate layer and the bottom layer, and how strong this transport is with respect to the geostrophic flow (i.e., thermal wind), can be explored by means of Ekman layer thickness $h_{\mathrm{EK}} \approx(2 v / f)^{1 / 2}$. For a laminar case (Johnson et al., 1976) such a thickness is $\approx \mathrm{O}\left(10^{-1}\right) \mathrm{m}$, where $v$ is the fluid viscosity. All this demonstrates that for our case study the Ekman transport effect induced by the LIW on the EMDW is negligible. On the other hand, we stress that the effect of friction in the bottom layer is more complex, mostly in the sill region. Real seafloor is indeed irregular, with bathymetric heterogeneities of many space scales. This gives a much thicker benthic layer, i.e., $(2 K / f)^{1 / 2} \approx \mathrm{O}(10) \mathrm{m}$ for a turbulent viscosity $K \gg v$ (Salon et al., 2008). Moreover, Johnson 
et al. (1976) noted the occurrence of a secondary, frictionally induced cross-channel circulation, which forces spun-down fluid into the interior, further limiting the sill flow (see Fig. 5 of Johnson and Ohlsen, 1994).

Vorticity is therefore strongly affected by these frictional effects. Moreover, because the bottom frictional coefficient $K^{*}$ may reasonably vary along-stream due to the spatial pattern of bottom irregularities, the effect of friction on flow vorticity and PV may increase further.

\section{The vorticity equation}

By focusing on the narrow bottom layer $(j=3$, where the index " 3 " will be disregarded hereafter), we make use of a stream-tube model (Fig. 2b) in a stream-wise coordinate system $(\xi, \psi)$. In this frame, $\xi$ is the along-flow coordinate, centered along the mid-line of the vein, and $\psi$ is the cross-flow coordinate (Smith, 1975; Killworth, 1977). Such a model is that of a steady flow where the bottom water is assumed to be well mixed. The flow has strong axial velocity nearly uniform over a cross section of the stream (i.e., $v \ll u$ is anti-symmetric and vanishes at the vein lateral boundaries $\psi= \pm W / 2$; Baringer and Price, 1997b). Therefore, the cross-stream scale is assumed to be much smaller than the local radius of curvature of the stream axis. All this implies that the velocity of a stream line is a function of $\xi$ only. The angle between the stream-tube axes $(\xi, \psi)$ and the fixed axes $(x, y)$ is $\beta$ (Fig. 2b). Consequently, in this new frame, the horizontal gradient operator can be written as (Smith, 1975)

$$
\begin{aligned}
& \nabla_{h}=\left(\frac{1}{1-\psi \frac{\partial \beta}{\partial \xi}} \frac{\partial}{\partial \xi},\left(\frac{\partial}{\partial \psi}-\frac{\frac{\partial \beta}{\partial \xi}}{1-\psi \frac{\partial \beta}{\partial \xi}}\right)\right) \\
& \approx\left(\frac{\partial}{\partial \xi}, \frac{\partial}{\partial \psi}\right)
\end{aligned}
$$

where the approximation on the right of the $\approx$ of Eq. (4) is justified by a small $\psi \frac{\partial \beta}{\partial \xi}$, as for the Sicily Channel case (Fig. 1), where $\beta$ is close to zero because of the straight E$\mathrm{W}$ path of the bottom vein (see Sect. 7).

By cross-differentiating the horizontal components of Eq. (2) for a dense water streamline, one obtains the classical vorticity equation (Gill, 1982; p. 231)

$$
\frac{\mathrm{d}}{\mathrm{d} t} \zeta+(\zeta+f)(\operatorname{div} \boldsymbol{u})=\frac{1}{\rho}(\operatorname{curl} \boldsymbol{F})_{z}
$$

which, in steady state, is

$u \frac{\partial}{\partial \xi} \zeta+(\zeta+f)(\operatorname{div} \boldsymbol{u})=\frac{1}{\rho}(\operatorname{curl} \boldsymbol{F})_{z}$

It is useful to recall that $\zeta$, in Eqs. (5) and (6), is the sum of a "shear vorticity", related to the lateral shear of the current, and a "curvature vorticity" due to the bending streamline of the current (Holton, 1972; Chen et al., 1992). The frictional term in Eqs. (5) and (6) can be explicated as $\frac{1}{\rho}(\operatorname{curl} \boldsymbol{F})_{z}=$ $-K \zeta$. We finally emphasize that our Eq. (6) looks rather different from the steady, quasi-geostrophic, and inviscid version proposed by Hogg (1983):

$\left(\frac{\partial v}{\partial \xi}+f\right) u-\frac{\partial}{\partial \psi} B=0$,

where $B=\frac{p}{\rho}+\frac{v^{2}}{2}$ is the Bernoulli function.

Equation (6), once integrated, gives an exact diagnostic relation for the spatial evolution of $\zeta$ by assuming the knowledge of $h(\xi, \psi)$ and $u(\xi, \psi)$ :

$$
\begin{aligned}
& \frac{\zeta}{f}=e^{-\int_{0}^{\xi} \frac{1}{u}(X+\operatorname{div} \boldsymbol{u}) \mathrm{d} x} \\
& \left\{\frac{\zeta_{0}}{f}-\int_{0}^{\xi} e^{\int_{0}^{x} \frac{1}{u}(X+\operatorname{div} \boldsymbol{u}) \mathrm{d} x^{\prime}} \frac{1}{u}(\operatorname{div} \boldsymbol{u}) \mathrm{d} x\right\} .
\end{aligned}
$$

Let us also note that an approximated solution of Eq. (6) for $\zeta \ll f$ is

$$
\frac{\zeta}{f}=e^{-\int_{0}^{\xi} \frac{X}{u} \mathrm{~d} x}\left\{\frac{\zeta_{0}}{f}-\int_{0}^{\xi} e^{\int_{0}^{x} \frac{X}{u} \mathrm{~d} x^{\prime}} \frac{1}{u}(\operatorname{div} \boldsymbol{u}) \mathrm{d} x\right\} .
$$

Intuitively, the two solutions, Eqs. (8) and (9), are rather similar, although Eq. (9), analytically speaking, is relatively more subject to eventual irregularities in the flow velocity $u$, such as sharp and large peaks around the sill region. Moreover, we note that the approximation that leads to Eq. (9) cannot be applied near the sill of a channel if the flow there is subject to hydraulic control.

In real field cases, the knowledge of $h(\xi, \psi)$ and $u(\xi, \psi)$ is often difficult to infer form in situ hydrographic data. By seeking a more applicable relation, we therefore consider cross sectional averages of the various terms of Eq. (6). This leads to the following solution for $\bar{\zeta} \ll f$ (Appendix A):

$$
\frac{\bar{\zeta}}{f}=e^{-\int_{0}^{\xi} \overline{\frac{X}{u}} \mathrm{~d} x}\left\{\frac{\bar{\zeta}_{0}}{f}-\int_{0}^{\xi} e^{\int_{0}^{x} \frac{X}{\bar{u}} \mathrm{~d} x^{\prime}} \frac{1}{\bar{u}}(\overline{\operatorname{div} \boldsymbol{u}}) \mathrm{d} x\right\},
$$

where the overbars indicate the cross-channel average.

Such a cross-averaging approach is further justified by the fact that the bottom vein is assumed to flow along a narrow and long channel, where the longitudinal length scale is greater than the transversal scale. In this way, one can diagnose the cross-channel average of flow vorticity $(\bar{\zeta})$ from the experimental knowledge of the cross-channel averaged $\bar{h}$ and $\bar{u}$, which are bulk quantities easily inferable from in situ measurements. Moreover, the cross-channel averaging allows for further perturbations to be avoided that can be given by waves occurring along the lateral edges of the current, which are known, however, to have a small local effect (Lacombe and Richez, 1982; Pratt et al., 2008). Similar 
discussions can be had regarding the presence of upper and bottom Ekman boundary layers, which can perturb the nonaveraged vorticity field, as was found in the study of Johnson and Ohlsen (1994).

\section{Continuity equation and vertical entrainment}

To include dynamical effects due to entrainment between the two lowest, cross sectionally homogeneous layers, we consider here the mass continuity equation (Appendix A)

$\frac{\mathrm{d}}{\mathrm{d} t} \bar{h}+\bar{h} \operatorname{div} \boldsymbol{u}=E\left|\bar{u}-\bar{u}_{2}\right|$

or, in steady state,

$\bar{u} \frac{\partial}{\partial \xi} \bar{h}+\bar{h} \overline{\operatorname{div} \boldsymbol{u}}=E\left|\bar{u}-\bar{u}_{2}\right|$,

where $E\left|\bar{u}-\bar{u}_{2}\right|$ describes the vertical displacement of the interface between the two lowest layers due to mixing. Layer 2 (i.e., the middle layer; Fig. $2 \mathrm{a}$ ) has velocity $\left(\bar{u}_{2}, 0\right)$, and the entrainment dimensionless parameter $\mathrm{E}$ is assumed to be $\sim 10^{-4}$ (Ellison and Turner, 1959; Turner, 1986). Entrainment also implies an exchange of momentum between layers, and thus an additional resistive force (Baringer and Price, 1997b; Gerdes et al., 2002) that should be considered in the momentum balance. However, if $\bar{u}$ is $\sim \bar{u}_{2}$ (Tables 1 and 2), momentum variations due to entrainment can be reasonably neglected as previously discussed.

We finally point out that the continuity Eqs. (11) and (12) can be formulated if one assumed that both velocity and density profiles within the bottom layer exhibit similarity forms, so that the rate of entrainment may be related solely to the mean velocity and the layer thickness (Smith, 1975).

\section{Vorticity equation with entrainment}

By substituting the $\overline{\operatorname{div} \boldsymbol{u}}$ in Eq. (10) with that from Eq. (12), one obtains

$$
\begin{aligned}
& \frac{\bar{\zeta}}{f}=\frac{\bar{u}_{0}}{\bar{u}} e^{-\int_{0}^{\xi} \frac{X}{\bar{u}} \mathrm{~d} x} \\
& \left(\frac{\bar{\zeta}_{0}}{f}+\frac{1}{\bar{u}_{0}} \int_{0}^{\xi} e^{\int_{0}^{x} \frac{X}{\bar{u}} \mathrm{~d} x^{\prime}}\left[\frac{\bar{u}}{\bar{h}} \frac{\partial \bar{h}}{\mathrm{~d} x}-\frac{1}{\bar{h}} E\left(\bar{u}-\bar{u}_{2}\right)\right] \mathrm{d} x\right),
\end{aligned}
$$

while, disregarding the entrainment, Eqs. (10) and (12) simply give

$$
\frac{\bar{\zeta}}{f}=\frac{\bar{u}_{0}}{\bar{u}} e^{-\int_{0}^{\xi} \frac{X}{\bar{u}} \mathrm{~d} x}\left(\frac{\bar{\zeta}_{0}}{f}+\frac{1}{\bar{u}_{0}} \int_{0}^{\xi} e^{\int_{0}^{x} \frac{X}{\bar{u}} \mathrm{~d} x^{\prime}} \frac{\bar{u}}{\bar{h}} \frac{\partial \bar{h}}{\mathrm{~d} x} \mathrm{~d} x\right) .
$$

Note that, for the sake of simplicity, we hereafter omit overbars on all the cross-channel averaged variables.
Equation (13a) and (13b) show that the main forcing on $\zeta$ is given by (i) a vorticity stretching term $\frac{u}{h} \frac{\partial h}{\partial \xi}$ (Gill, 1977), (ii) the entrainment effect, and (iii) friction. In particular, we note that

1. $\zeta$ is the sum of an initial condition $\left(\zeta_{0}\right)$ plus the integral of both stretching and entrainment terms $\left[\frac{u}{h} \frac{\partial h}{\partial x}-\frac{1}{h} E\left(u-u_{2}\right)\right]$ due to bathymetric forcing and vertical mixing, respectively.

2. The entrainment term $\frac{1}{h} E\left(u-u_{2}\right)$ is, however, small for $u \approx u_{2}$, a condition that occurs when the two adjacent bottom and intermediate layers flow in the same direction.

3. Both initial condition and stretching terms are multiplied by $\frac{u}{u_{0}} e^{-\int_{0}^{\xi} \frac{X}{u} \mathrm{~d} x}$, which is related to friction, and it vanishes progressively over a distance $\sim 3 u / X$. One can therefore argue that the role of frictional effects largely depend on the friction function $X$ and thus on the local sea-bottom roughness.

All these features are particularly valid where topographic changes are significant and therefore represent general effects for deep, steady, baroclinic currents in marine channels, straits, and ridges.

Our considerations imply that the evolution of $\zeta / f$ is not strictly related to the initial or downstream conditions but rather that it is mainly ruled by $\frac{u}{h} \frac{\partial h}{\partial x}$. Indeed, upstream of the sill of a marine channel $\frac{u}{h} \frac{\partial h}{\partial \xi} \leq 0$, while $\frac{u}{h} \frac{\partial h}{\partial \xi}$ becomes positive downstream, which means that $\zeta$ must decrease as the sill is approached, eventually becoming negative. Once downstream of the sill, $\zeta$ will increase again, reaching preexisting upstream values. This is an important point since it differs from classical stream-tube models that require, for hydraulically supercritical flows, the integral from the upstream location to be taken in order to obtain solutions for $\zeta$. Moreover, "if the ordinary differential equation can be solved analytically in closed form, the constant of integration in the analytic solution can be determined from the boundary condition; consequently, the location of the control section, where the boundary condition is prescribed, is of no concern" (Jain, 2001).

\section{PV equation}

By combining Eqs. (5) and (11), for cross section averaged quantities, one obtains the shallow-water vertical PV equation 
Table 1. Main experimental quantities measured by A01 in the Sicily Channel and in the southern Tyrrhenian Sea during the MATER II cruise (Figs. 1 and 3). Here $\sigma_{\text {bottom }}$ is the maximum $\sigma_{\theta}$ observed in the hydrographic casts; $h$ is the bottom-layer thickness; $g^{\prime}$ the reduced gravity; $\varphi(\mathrm{EMDW})$ is the EMDW volume transport; the Froude number is $F r$; the entrainment parameter $E^{*}$ is the one computed by Baringer and Price (1997b). * LIW and EMDW velocities for section III were obtained from current-meter measurements. Velocities for the sections were obtained by using continuity, considering the total transport and dividing by the cross sectional area.

\begin{tabular}{|c|c|c|c|c|c|c|c|c|}
\hline Transect & I & II & III & IV & V & VIc & VII & Units \\
\hline$\sigma_{\text {bottom }}$ & 29.168 & 29.165 & 29.163 & 29.157 & 29.150 & 29.124 & 29.117 & $\mathrm{~kg} \mathrm{~m}^{-3}$ \\
\hline$h$ & 120 & 150 & 140 & 100 & 50 & 150 & 200 & $\mathrm{~m}$ \\
\hline$g^{\prime}$ & 3 & 3 & 4 & 6 & 6 & 3 & 2 & $10^{-4} \mathrm{~ms}^{-2}$ \\
\hline Bottom depth & 550 & 600 & 800 & 530 & 350 & 600 & 1200 & $\mathrm{~m}$ \\
\hline $\begin{array}{l}\text { Distance between } \\
\text { transects }\end{array}$ & 0 & 80 & 135 & 170 & 25 & 65 & 25 & $\mathrm{~km}$ \\
\hline$W$ & 20 & 80 & 40 & 15 & 15 & 30 & 20 & $\mathrm{~km}$ \\
\hline$u_{2}(\mathrm{LIW})$ & 12 & 5 & 3.2 & 18 & 53 & 11 & 7 & $\mathrm{cms}^{-1}$ \\
\hline$u_{3}(\mathrm{EMDW})$ & 13 & 8 & 5 & 14 & 46 & 15 & 17 & $\mathrm{cms}^{-1}$ \\
\hline$\varphi($ EMDW $)$ & 0.23 & 0.26 & 0.20 & 0.23 & 0.32 & 0.35 & 0.34 & $\mathrm{~Sv}$ \\
\hline$F_{r}=\frac{u-u_{2}}{\sqrt{g^{\prime} h}}$ & 0.1 & 0.2 & 0.1 & 0.2 & 0.8 & 0.2 & 0.5 & \\
\hline$E^{*}$ & / & $\sim 0$ & $10^{-5}$ & $10^{-4}$ & $2 \times 10^{-4}$ & $9 \times 10^{-4}$ & $3 \times 10^{-4}$ & \\
\hline
\end{tabular}

\subsection{Sicily Channel hydrographic settings}

$\left(\frac{\mathrm{d}}{\mathrm{d} t}+\Gamma\right) \Pi=\frac{(\operatorname{curl} \boldsymbol{F})_{z}}{\rho h}=-\frac{X \zeta}{h}$,

with $\Pi=\frac{\zeta+f}{h}$ and $\Gamma=\frac{E\left|u-u_{2}\right|}{h}$.

Cross-channel vertical sections of potential temperature $(\theta)$ and salinity $(S)$ along the whole Sicily Channel were performed by A01 during MATER II (10-31 January 1997) and MATER IV (21 April-14 May 1998) cruises (Fig. 1a) in order to investigate the three-layer flow properties, in particular, around the western sill (Figs. 3 and 4). CTD (conductivity-temperature-depth) casts were collected over a regular grid (CTD stations $\sim 9 \mathrm{~km}$ apart from each other; near the sill the distance was reduced to $\sim 5 \mathrm{~km}$ ).

The analysis of potential density $(\sigma), \theta$, and $S$, combined which can be significantly simplified if the exponential length scale $u / \Gamma$ in Eq. (15a) is much larger than the channel length:

$\Pi \approx \Pi_{0}-\int_{0}^{\xi} \frac{X \zeta}{h u} \mathrm{~d} x$.

Equation (15a) and (15b) confirm that variations in $\zeta$ and $h$, along with frictional effects represented by the presence of $X$, play a direct role in $\Pi$ variations. Moreover, because $u, h$, and $X$ are, in general, rather regular and positive quantities, while $\zeta$ is much more variable, Eqs. (14) and (15) suggest that for positive $\zeta$ and weak friction - as occurs upstream of a sill $-\Pi$ must decrease, whereas for a negative $\zeta$ and strong friction at the sill region, $\Pi$ increases.

\section{Diagnostic analysis in the Sicily Channel}

We now analyze Eqs. (14) and (16), namely, $\zeta(\xi)$ and $\Pi(\xi)$, for the realistic case of the EMDW flowing through the Sicily Channel (Fig. 1). with the assumption that the LIW flux is conserved, allowed A01 to estimate the thickness and cross sectional areas of EMDW, LIW, and MAW layers (Table 1). Current-meter measurements were also collected over the western sill (i.e., section IV) and in correspondence with section V (Figs. 1, 3, and 4). These measurements allowed us to estimate EMDW and LIW velocities for all sections with the use of continuity. The upper part of LIW was defined by $\sigma \sim 28.80$ and the interface between LIW and EMDW by $\sigma \sim 29.11-29.16$ (Figs. 3 and 4). The EMDW was defined by using $\theta-S$ diagrams, recognizing the bottom density observed along each transect.

A01 analysis showed that the EMDW enters the channel from the east at a depth of $\sim 400-550 \mathrm{~m}$, banked against the Sicilian shelf break (Figs. 1b, 3, and 4). There, the width $(W$ ) of the current is about $20 \mathrm{~km}, \sigma$ is $\sim 29.17$, the crosschannel averaged velocity $\bar{u}$ is $12-13 \mathrm{~cm} \mathrm{~s}^{-1}$, and the crosschannel averaged thickness $\bar{h}$ is $\sim 75-120 \mathrm{~m}$ (Tables 1 and 2). Further west, the EMDW was observed to sink to depths greater than $700 \mathrm{~m}$ (transect III in Figs. 3 and 4), rising again to $300-350 \mathrm{~m}$ depth at the western sill but, rather surpris- 

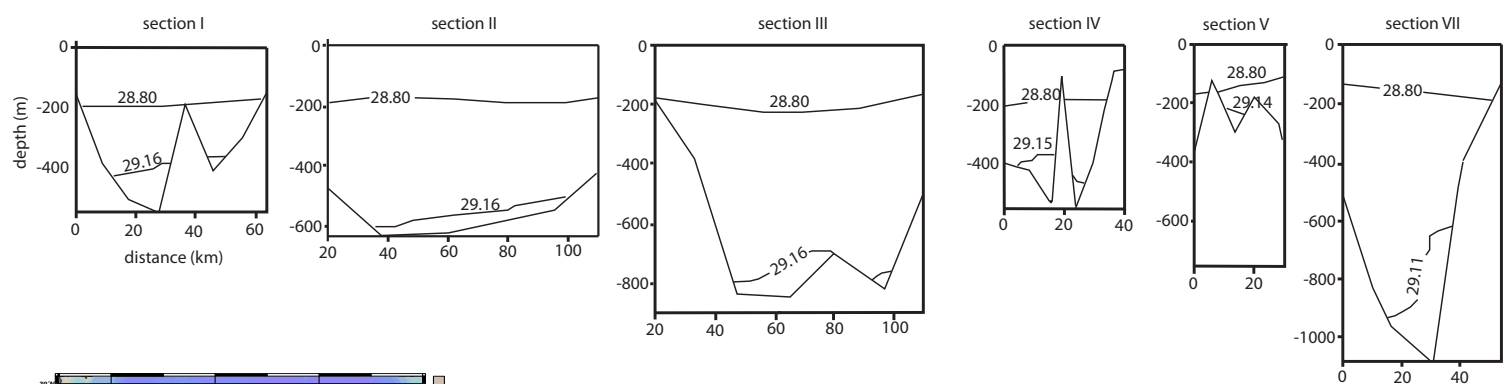

(a)
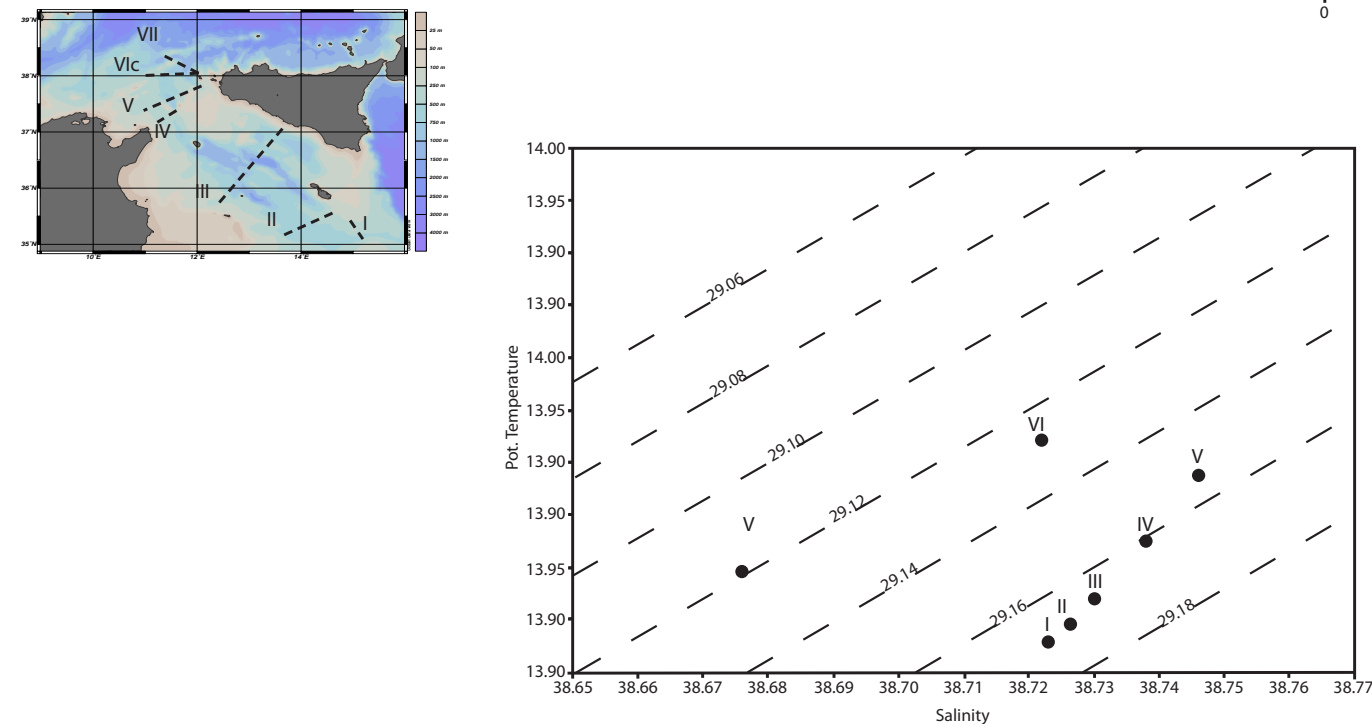

(b)

Figure 3. MATER II cruise (January 1997): (a) characteristic isopycnal cross sections between MAW, LIW, and EMDW. In these sections, Tunisia is on the left side. Note that, in section IV, the EMDW flows only in the western passage of the cross section; interfacial slope modification is also visible in section V. (b) Evolution of $\theta-S$ values of EMDW close to the bottom. From Astraldi et al. (2001).

ingly, banked against the Tunisian shelf break (transects IV$\mathrm{V})$. There, $W$ is $\sim 8-15 \mathrm{~km}, \sigma$ is $\sim 29.15, \bar{h}$ is $\sim 25-50 \mathrm{~m}$, and $\bar{u}$ reaches $\sim 27-46 \mathrm{~cm} \mathrm{~s}^{-1}$. At the western mouth of the channel the EMDW sinks again along the Sicilian coast at $\sim 1100-1200 \mathrm{~m}$ (transect VII). Then, it attains a buoyancy equilibrium in the southern Tyrrhenian Sea, where $W$ is $\sim 20 \mathrm{~km}, \sigma$ is $\sim 29.12, \bar{u}$ is $\sim 8-17 \mathrm{~cm} \mathrm{~s}^{-1}$, and $\bar{h}$ is $\sim 130$ $200 \mathrm{~m}$ (Sparnocchia et al., 1999; Figs. 3 and 4). This final sinking is made possible by the small density of the Tyrrhenian LIW $(\sigma \sim 29.05)$.

The initial $\theta-S$ characteristics of the EMDW at the eastern entrance are progressively modified along the vein route (Figs. 3 and 4). These changes are rather weak east of the sill and within the channel, while they become larger in the region west of the sill. The most substantial changes in the hydrographic characteristics are observed between sections V and VII: a gradual increase of both temperature and salinity, indicates a progressive lightening of EMDW from section I (eastern sill) to section VI. This stresses the important role of friction and mixing around the sill region in modifying the hydrographic characteristics of the bottom water.

From these data, A01 also estimated Rossby $(R o \sim 0.1)$ and Froude numbers. Far from the sill, the EMDW was char- acterized by a Froude number of $F r \sim 0.1$, a small value that would inhibit a strong mixing between LIW and EMDW. Over the sill $F r$ is $\sim 0.6-0.8$ (Tables 1 and 2 ). These values, however, are obtained from time averaging and thus depict a steady condition (A01). We believe that $F r$ may reach higher values during strong transient phenomena.

Finally, by assuming quadratic friction, $\boldsymbol{F}=-K^{*} \frac{\rho \bar{u}}{\bar{h}} \boldsymbol{u}$, A01 estimated a dimensionless frictional coefficient, $K^{*}=$ $2.6 \times 10^{-2}$, from the vein momentum balance. This value is rather large with respect to those proposed in the literature which lie within the range of $2-12\left(\times 10^{-3}\right)$ (Baringer and Price, 1997b) - and is likely justified by the very irregular topography of the Sicily Channel around the sill region.

\subsection{Diagnostic analysis for vorticity and PV}

From hydrographic and current-meter data for the abovedescribed EMDW, we perform a scale analysis of Eq. (5): considering $L \sim 10^{5} \mathrm{~m}$ and $W \sim 10^{4} \mathrm{~m}$ as the along-channel and cross-channel space scales, respectively, and $U \sim$ 

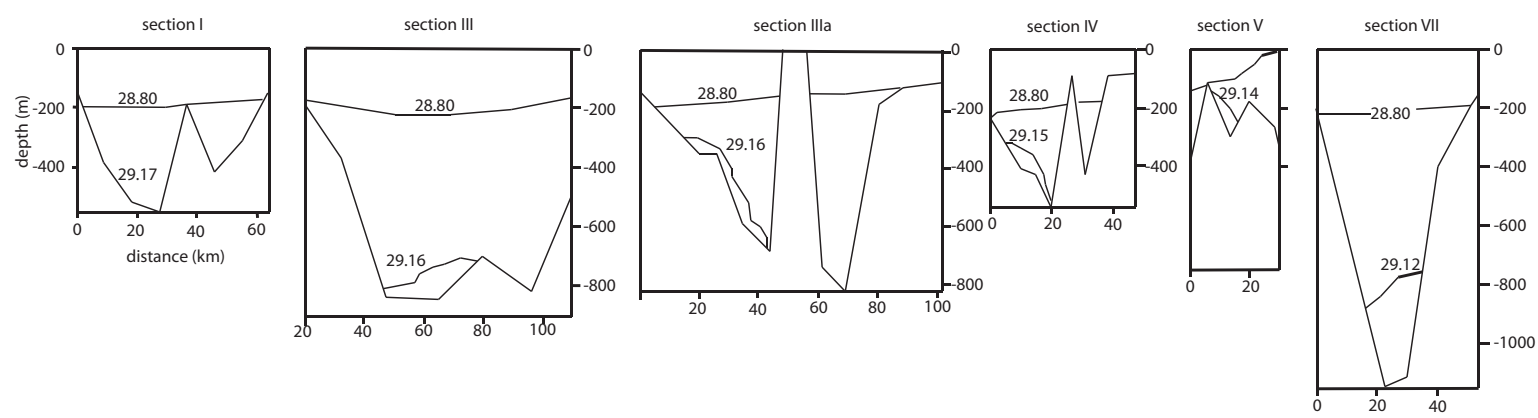

(a)
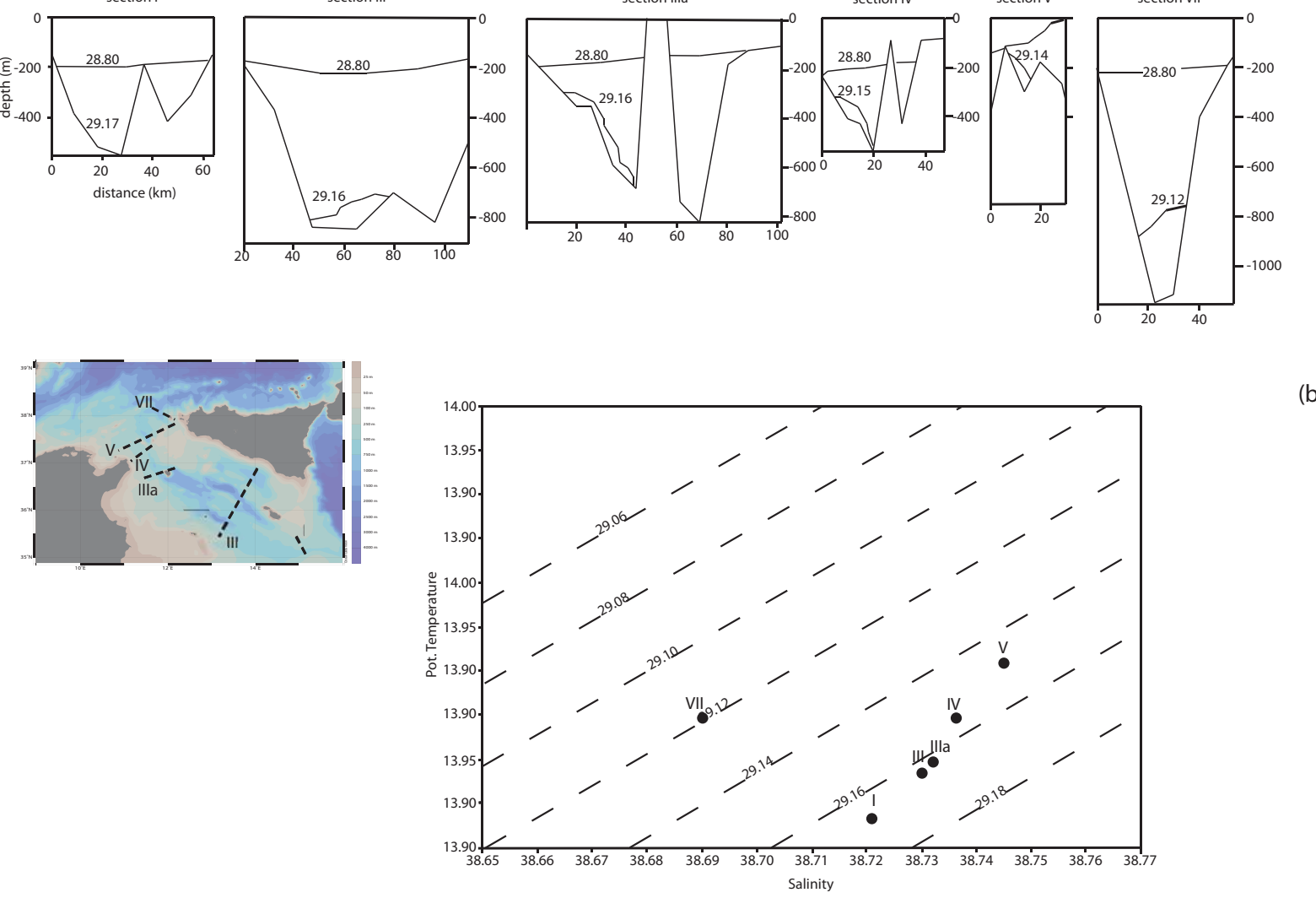

(b)

Figure 4. MATER IV cruise (April-May 1998): (a) characteristic isopycnal cross sections between surface Atlantic water, LIW, and EMDW. In these sections, Tunisia is on the left side. Note that, in section III, the EMDW flows only in the western passage of the cross section; interfacial slope modification is also visible in sections III, IV, and V (b) Evolution of $\theta-S$ values of EMDW close to the bottom. From Astraldi et al. (2001).

$10^{-1} \mathrm{~ms}^{-1}$ as the along-channel velocity, we obtain

$u \frac{\partial}{\partial \xi} \zeta+(\zeta+f)(\operatorname{div} \boldsymbol{u})=-X \zeta$

$\frac{U}{L}\left(\frac{U}{R}+\frac{U}{W}\right)+\left(\frac{U}{R}+\frac{U}{W}+f\right)\left(\frac{U}{L}\right)=X\left(\frac{U}{R}+\frac{U}{W}\right)$

$\frac{1}{T}\left(10^{-6}+10^{-5}\right)+\frac{1}{T}\left(10^{-6}+10^{-5}+10^{-4}\right)$

$=10^{-6} \times 10^{-4}$

where $T \sim 10^{4-5} \mathrm{~s}$ is the EMDW timescale, $f$ is $\sim 10^{-4} \mathrm{~s}^{-1}$, and $R \sim 10^{5} \mathrm{~m}$ is an estimated curvature radius for the EMDW pathway around the sill region; the friction coefficient $X \sim 10^{-5} \mathrm{~s}^{-1}$ is estimated by considering the value proposed by A01 (i.e., $K^{*}$ ) multiplied by $U^{2} / H \sim 10^{-4} \mathrm{~s}^{-1}$ (where $H \sim 100 \mathrm{~m}$ scales for the EMDW thickness). We remark that $\zeta$ in Eq. (16) is the sum of a "shear vorticity" $\left(U / W \sim 10^{-5} \mathrm{~s}^{-1}\right.$ in the Sicily Channel) and a "curvature vorticity" ( $U / R \sim 10^{-6} \mathrm{~s}^{-1}$ in the Sicily Channel) due to the bending pathway of the EMDW.

The scale analysis in Eq. (16) shows that each term of Eq. (5), and thus of Eq. (14), plays a role in the EMDW dy- namics. Friction, in particular, is a crucial term in the alongchannel evolution of $\zeta$ and makes for a non-conservative PV. Moreover, since (i) $\zeta \ll f$ in Eq. (16), (ii) $u \approx u_{2}$ in Eq. (13a), and (iii) the length scale $u / \Gamma \sim 10^{6} \mathrm{~m}$ in Eq. (15) results in being larger than the entire channel length, one can reasonably use the approximated solutions for vorticity and PV in Eqs. (13b) and (15b). From these considerations we therefore expect a negative trend for $\zeta$ when approaching the sill region, followed by a positive trend and a rather large peak of $\Pi$ immediately after the sill, as confirmed by the detailed results we describe below. The following analysis of Eqs. (13) and (15) in their closed form is performed by using continuous functions for $u(\xi)$ and $h(\xi)$, which are computed from modified spline interpolations of $\bar{u}_{i}$ and $\bar{h}_{i}$ as obtained from the in situ data (Appendix B). Velocity interpolations are also compared with Protheus numerical data (Fig. 5), a relatively coarse-resolution Mediterranean model $\left(1 / 8^{\circ} \times 1 / 8^{\circ}\right)$ based on the MIT general circulation model (MITgcm; Sannino et al., 2009; Sannino, personal communication), and show fair agreement with the splines. Due to the coarse vertical resolution of this model, such a comparison cannot be provided for the bottom water thickness $\bar{h}_{i}$. 
Table 2. As Table 1, but for the MATER IV cruise (Figs. 1 and 4).

\begin{tabular}{lrrrrrrl}
\hline Transect & I & III & IIIa & IV & V & VII & Units \\
\hline$\sigma_{\text {bottom }}$ & 29.167 & 29.165 & 29.163 & 29.156 & 29.148 & 29.119 & $\mathrm{~kg} \mathrm{~m}^{-3}$ \\
$h$ & 75 & 125 & 100 & 50 & 25 & 130 & $\mathrm{~m}$ \\
$g^{\prime}$ & 8.3 & 8.2 & 8 & 7.8 & 7.4 & 6 & $10^{-4} \mathrm{~m} \mathrm{~s}^{-2}$ \\
Bottom depth & 550 & 700 & 650 & 500 & 360 & 1150 & $\mathrm{~m}$ \\
Distance between & & 155 & 170 & 60 & 25 & 90 & $\mathrm{~km}$ \\
transects & & & & & & & \\
$W$ & 15 & 5 & 22 & 15 & 8 & 18 & $\mathrm{~km}$ \\
$u_{2}$ (LIW) & 10 & 2 & 12 & 13 & 35 & 5 & $\mathrm{~cm} \mathrm{~s}^{-1}$ \\
$u_{3}$ (EMDW) & 12 & 6 & 3 & 8 & 27 & 8 & $\mathrm{~cm} \mathrm{~s}^{-1}$ \\
$\varphi$ (EMDW) & 5 & 5.4 & 7.2 & 8 & 10 & 12 & $10^{-2} \mathrm{~Sv}$ \\
$F_{r}=\left|\frac{u-u_{2}}{\sqrt{g^{\prime} h}}\right|$ & 0.1 & 0.05 & 0.3 & 0.2 & 0.6 & 0.03 & \\
$E^{*}$ & $2 \times 10^{-5}$ & $10^{-5}$ & $1.3 \times 10^{-4}$ & $4 \times 10^{-4}$ & $4.5 \times 10^{-4}$ & $3 \times 10^{-4}$ & \\
\hline
\end{tabular}
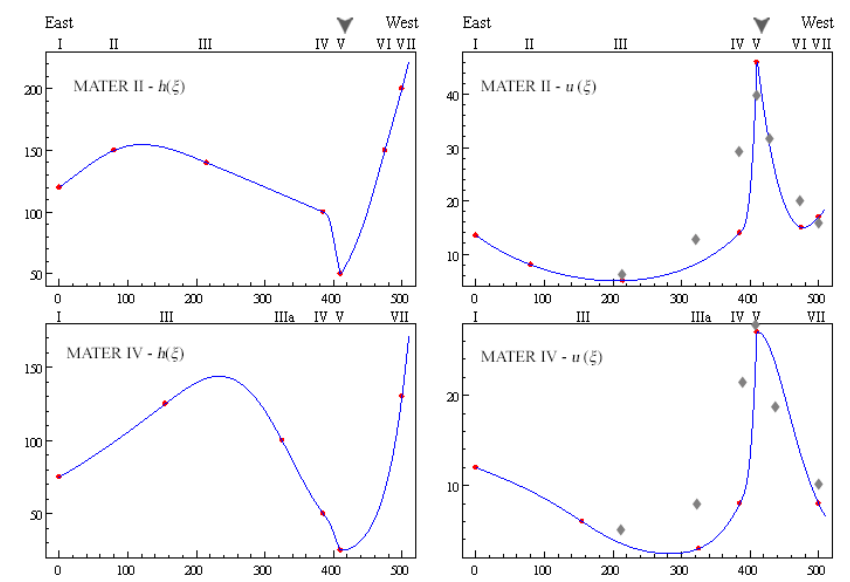

Figure 5. Modified spline interpolation of $h_{i}$ (m) and $u_{i}$ in $\left(\mathrm{cm} \mathrm{s}^{-1}\right)$ along $\xi(\mathrm{km})$; Roman numerals indicate hydrograph transects shown in Figs. 3 and 4, for MATER II cruise and MATER IV, respectively. The black arrows at the top show the position of the sill. Diamonds represent the cross sectional maximum velocities as obtained by the Sannino et al. (2009) numerical model (see text).

\section{MATER II cruise (January 1997)}

For this data set (Figs. 3 and 5, Table 3), we see that both $\zeta$ and $\Pi$ are rather small upstream of the sill, namely, $\zeta \sim$ $5 \times 10^{-6} \mathrm{~s}^{-1}$ or less and $\Pi \sim 8 \times 10^{-7} \mathrm{~s}^{-1} \mathrm{~m}^{-1}$ (Fig. 6). Approaching the sill, vorticity changes sign (Fig. 6) due to the stretching term $\frac{u}{h} \frac{\partial h}{\partial \xi}$ in Eq. (13). A negative value $\zeta \sim-6 \times 10^{-5} \mathrm{~s}^{-1}$ is then reached at transect IV, and consequently $\Pi$ reaches a very large peak $\sim 6 \times 10^{-6} \mathrm{~s}^{-1} \mathrm{~m}^{-1}$ at transect V. Downstream of the sill, in the southern Tyrrhenian Sea, $\zeta$ again has a positive value, $\zeta \sim 6 \times 10^{-5} \mathrm{~s}^{-1}$, and $\Pi$ strongly decreases to $8 \times 10^{-7} \mathrm{~s}^{-1} \mathrm{~m}^{-1}$ (Fig. 6).

\section{MATER IV cruise (April-May 1998)}

This springtime data set (Figs. 4 and 5, Table 4), although similar to the one described above, shows lower velocities and fluxes than those of the winter case (Fig. 6; Stansfield et al., 2001). Upstream of the sill $\zeta$ is $\sim 5 \times 10^{-6} \mathrm{~s}^{-1}$ and $\Pi$ is $\sim 1 \times 10^{-6} \mathrm{~s}^{-1} \mathrm{~m}^{-1}$, while, for a region about $120 \mathrm{~km}$ long before the sill, $\zeta$ goes from $\sim 10^{-6}$ to $-7 \times 10^{-5} \mathrm{~s}^{-1}$. In the same way, $\Pi$ goes from $\sim 10^{-6} \mathrm{~s}^{-1} \mathrm{~m}^{-1}$ to $\sim 6 \times$ $10^{-6} \mathrm{~s}^{-1} \mathrm{~m}^{-1}$ immediately after the sill (Fig. 6). In the southern Tyrrhenian Sea, downstream of the sill, $\zeta \sim 4 \times 10^{-5} \mathrm{~s}^{-1}$. This shows a sudden change in vorticity, as for the MATER II cruise data (Fig. 6). Accordingly, $\Pi$ decreases strongly from the largest value at the sill to $\sim 1.5 \times 10^{-6} \mathrm{~s}^{-1} \mathrm{~m}^{-1}$ in the Tyrrhenian Sea, and then strongly decreases.

\section{Discussions}

The lack of specific current-meter measurements does not allow for a realistic determination of vorticity and, in particular, for a validation of our model. Moreover, the use of available numerical outputs in order to validate and/or compare our analytic results is not an easy task due to grid problems (G. Sannino, personal communication, 2015; L. Palatella, personal communication, 2015): spatial (vertical and horizontal) resolutions are often too coarse and, in particular, bottom velocities are available on very few cross-stream grid points (i.e., one or two at the western sill).

A rough, although reasonable, way to infer the EMDW vorticity independently from our model is given by the following considerations: since the EMDW path is rather straight upstream of the sill (Fig. 1), the curvature vorticity of this flow along the upstream region of the channel is very small (Holton, 1972). Therefore, initial values of vorticity for our analysis are taken from the shear vorticity only, which is approximately $\zeta_{0} \sim U / W$ (Fig. 6). Although this approxima- 

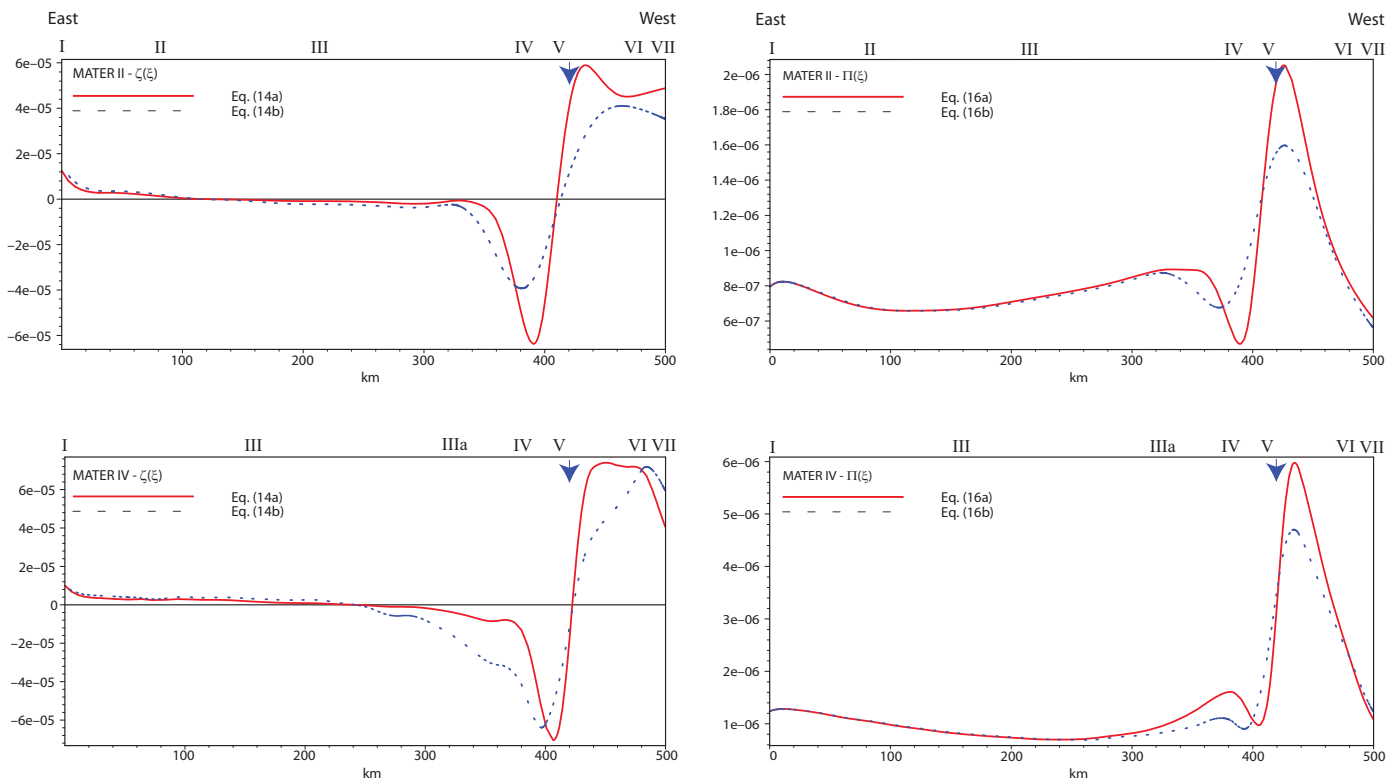

Figure 6. Analytic profiles for $\zeta(\mathrm{s}-1)$ and $\Pi\left(\mathrm{m}^{-1} \mathrm{~s}^{-1}\right)$ along $\xi(\mathrm{km})$ as obtained from Eqs. (13) and (15), respectively. The dashed lines indicate approximate solutions for $\zeta \ll f$ and $\frac{1}{h} E\left(u-u_{2}\right) \approx 0$, i.e., Eq. (14b). Position of the transects is also shown (see Figs. 3 and 4$)$ for MATER II and MATER IV cruises. The arrows show the position of the sill.

tion - taken as an initial condition for our vorticity analysis - can be affected by a large error, Eq. (13) shows that the "memory" of the initial vorticity $\zeta_{0}$ vanishes within a few kilometers.

A different option for determining $\zeta$ is suggested through use of the classical $\Pi$ conservation: $\zeta=\frac{f h}{h_{\infty}}-f$ (Gill, 1982), where $h_{\infty}$ is the bottom depth far upstream, in the Ionian Sea. This suggests that a vorticity stream-wise profile should look approximately like the EMDW thickness profile. However, such an estimate of $\zeta$ only holds far from the sill, where friction and mixing certainly do not affect the deep current.

Our diagnosis, through use of the A01 experimental data set, confirms the "memory-loss" effect of upstream vorticity conditions due to the role of friction. We found that the region around the sill ( $\sim 70 \mathrm{~km}$ length) has an unexpected negative peak of $\zeta$ that, moreover, seems to also be in agreement with the EMDW-LIW interface tilting that occurs at the sill (Figs. 3 and 4) in terms of change in flow curvature.

Abrupt changes in vorticity are also reflected in the downstream evolution of PV, which is definitely not constant around the sill region. This interesting result points out that an increase in $\Pi$ violates the all those assumptions for flow stability theorems (see, for instance, Wood and McIntyre, 2010).

An interesting aside, we check the reliability of the idealized friction coefficient by investigating the balance of the PV Eq. (14) for the EMDW along-channel evolution. The nonlinear friction $\boldsymbol{F}=-K^{*} \frac{\rho \bar{u}}{\bar{h}} \boldsymbol{u}$ described above, with the constant friction coefficient $K^{*}=2.6 \times 10^{-2}$ (A01), gives the following PV balance:

$$
\begin{aligned}
& \left(\frac{\mathrm{d}}{\mathrm{d} t}+\Gamma\right) \Pi=\frac{(\operatorname{curl} \boldsymbol{F})_{z}}{\rho h} \approx-\frac{2 K^{*} u \zeta}{h^{2}} \\
& \sim 10^{-11} \mathrm{~m}^{-1} \mathrm{~s}^{-2} .
\end{aligned}
$$

Equation (17) is nicely satisfied in the upstream part of the Sicily Channel, while this agreement fails over the sill (Fig. 7). Therefore, to investigate such a discrepancy, we analyze

$$
\begin{aligned}
\varepsilon & =\left(u \frac{\partial}{\partial \xi}+\Gamma\right) \frac{\zeta+f}{h}-\frac{(\operatorname{curl} \boldsymbol{F})_{z}}{\rho h} \\
& =\left(u \frac{\partial}{\partial \xi}+\Gamma\right) \frac{\zeta+f}{h}+\frac{K^{*}}{h^{2}} u \zeta \\
& =\underbrace{u \frac{\mathrm{d}}{\mathrm{d} \xi} \Pi}_{\varepsilon_{1}}+\underbrace{\Gamma \Pi}_{\varepsilon_{2}}+\underbrace{\frac{K^{*}}{h^{2}} u \zeta}_{\varepsilon_{3}} \approx 10^{-10}-10^{-11} \mathrm{~s}^{-2} \mathrm{~m}^{-1} .
\end{aligned}
$$

We point out that the analysis of each term of Eq. (18) does not use the explicit solution for $\Pi$ in Eq. (15a) and (15b) but only the vorticity $\zeta(\xi)$ in Eq. (13) since $\Pi=\frac{\zeta+f}{h}$. All this represents therefore a sort of independent validation of the PV balance (17).

For both MATER cruises, the along-channel profiles of the three terms $\varepsilon_{1}, \varepsilon_{2}$, and $\varepsilon_{3}$ (Fig. 7) are rather small but never exactly balanced, in particular around the sill region. For the MATER IV cruise, which was characterized by lower velocities, this unbalance seems to be due to the variability of the entrainment term $\varepsilon_{2}$, when approaching the sill, and to the 

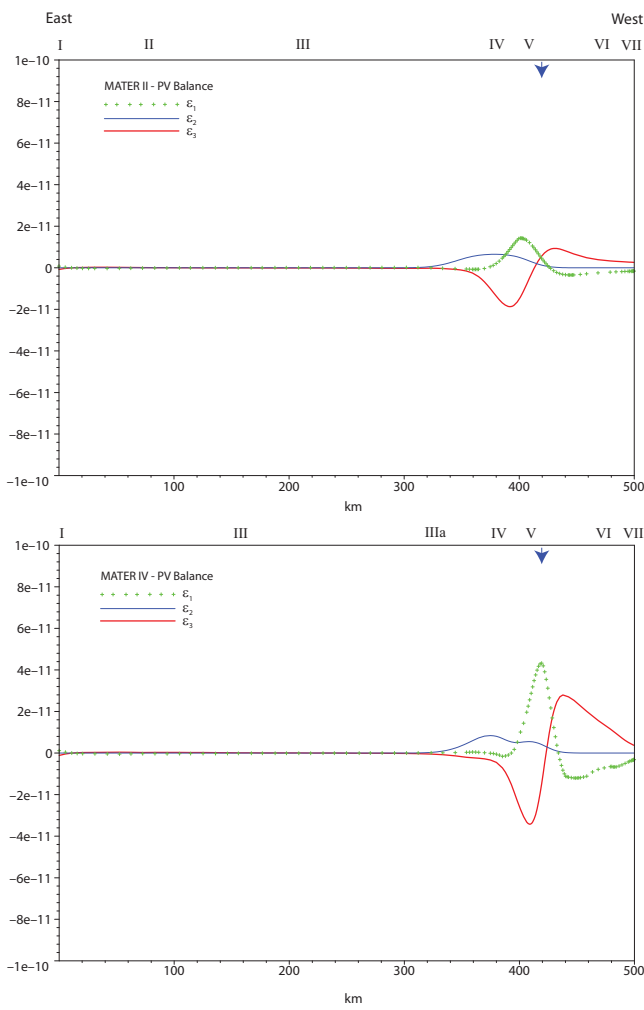

Figure 7. Analytic profile for the various terms in Eq. (18) along $\xi(\mathrm{m})$, namely, the friction term (bold line), the PV-advection term (dots line), and the entrainment term (thin line). Position of the transects is shown in Figs. 3 and 4, for the MATER II and MATER IV cruises, respectively. The black arrow shows the position of the sill.

advection term $\varepsilon_{1}$, which results in being too small for balancing the friction term $\varepsilon_{3}$.

This suggests that some tuning of the quadratic friction coefficient is needed. Consequently, we propose the use of a varying friction coefficient, namely, $K^{*} \rightarrow K^{*}+\chi^{*}(\xi)$. Indeed, large values of $\varepsilon$ around the sill (Fig. 7) suggest that both local roughness due to the sea-bottom morphology over the sill and an additional frictional effect due to the strong mixing occurring at the sill could affect the local schematization for friction. To optimize the balance of Eq. (18), we set

$0=u \frac{\partial}{\partial \xi} \Pi+\Gamma \Pi+\frac{K^{*}+\chi^{*}(\xi)}{h^{2}} u$,

which leads to local solutions for $\chi^{*}(\xi)$ (Fig. 8).

In the region where the bottom of the channel is rather flat, i.e., at $350 \mathrm{~km}$ from the beginning of the channel (around transect IIIa, Fig. 1), one obtains $\chi^{*}(\xi) \ll K^{*}$, in good agreement with the A01 coefficient. Then, approaching the sill, a $\sim 50 \%$ greater friction coefficient is required to satisfy Eq. (19) (Fig. 8). We note that a similar approach for seeking a more realistic frictional coefficient along particular morphological settings (such as straits and channels) was

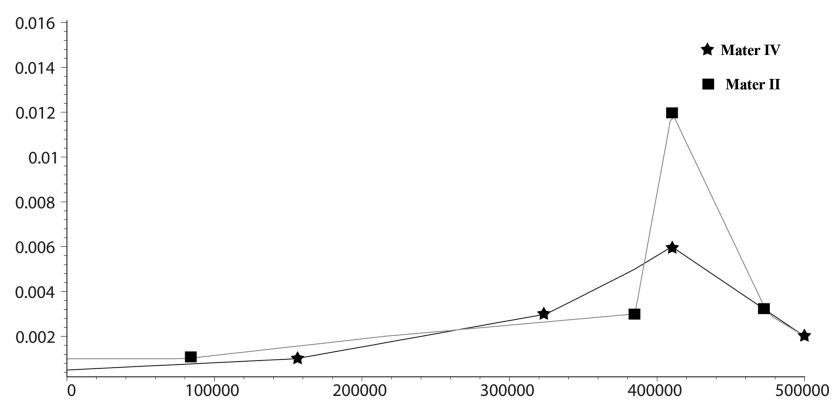

Figure 8. Variations in $\chi *$, defined as $K^{*} \rightarrow K^{*}+\chi *(\xi)$, along $\xi$ $(\mathrm{m})$, obtained through optimizing the balance of Eq. (19).

also pursued by Baringer and Price (1997a, b). Their results showed that (i) "large bottom friction coupled with the relatively small thickness of outflows may lead to a turbulent bottom boundary layer that extends over much of the total thickness of the outflow" and (ii) "the bottom stress appears to follow a quadratic drag law, though the appropriate $c_{D}$ (i.e., dimensionless friction coefficient) will vary considerably with the type of average velocity available for the parameterization". Both conclusions are in agreement with our results.

\section{Conclusions}

We investigated vorticity $(\zeta)$ and PV (П) evolution of the EMDW flowing along the Sicily Channel by making use of a shallow-water, stream-tube approach. The model allowed us to explore bottom current properties under the effect of seabottom changes, bottom friction, and vertical entrainment. Our analysis reveals sharp negative vorticity peaks over the sill region, while $\zeta$ again becomes positive downstream of the sill, as they were in the eastern basin. All this reflects on the PV behavior of the bottom currents, which experience large variations in $\Pi$, and reveals how PV-constant models are not suitable for exploring bottom currents dynamics along rotating channels. We argue that the along-channel evolution of both vorticity and PV is due to bathymetric effects occurring approaching the sill, which are also modulated by frictional effects that significantly change the structure of vorticity and $\mathrm{PV}$ equations for describing such dynamics.

Knowledge of the downstream evolution of $\zeta$ allowed us (i) to infer the deep vein dynamics, in particular, around the sill region, where frictional, entrainment, and stretching effects all play a crucial role; (ii) to diagnose the PV balance; and thus (iii) to tune the parameterization for bottom friction. In this regard, our analysis is a consequence of the steady, deep, and baroclinic current theory in marine straits (Smith, 1975; Killworth, 1977; Hogg, 1983) and it can provide analytical support to numerical and tank experiments aimed at the investigation of rotating hydraulic dynamics. 


\section{Appendix A: The cross sectional averages}

We evaluate here the cross sectional averages of various terms of the vorticity Eq. (7). Let us first assume that, for a narrow and long strait or channel, the derivative $\frac{\partial}{\partial \psi} a \gg \frac{\partial}{\partial \xi} a$ cross-strait, where $a$ is a general flow property. We then define the cross-channel average as $\bar{a}=\int a \mathrm{~d} z \mathrm{~d} \psi$.

For a nonlinear friction $\boldsymbol{F}_{n, m}=-K_{n, m} \frac{\rho}{\bar{h}^{m}} \bar{u}^{n} \boldsymbol{u} \equiv-\mathbf{X} \boldsymbol{u}$, the cross-channel averaging would therefore give

$\overline{\frac{1}{\rho}(\operatorname{curl} \boldsymbol{F})_{z}}=K \overline{\bar{u}} \frac{\overline{\partial u}}{\partial \psi}=-K \overline{\bar{h}} \bar{\zeta} \equiv-\mathrm{X} \bar{\zeta}$,

since $\bar{u}$ and $\bar{h}$ by definition are functions of $\xi$ only.

Accordingly, the second term on the left-hand side of the vorticity Eq. (6) can be averaged by considering that $\int \mathrm{d} \psi \partial_{\psi} v=0$ since $v$ is symmetric and vanishes at the vein lateral borders. Therefore, one obtains

$\overline{\operatorname{div} u} \equiv \int \mathrm{d} z \mathrm{~d} \psi\left(\partial_{\xi} u+\partial_{\psi} v\right)=\int \mathrm{d} z \mathrm{~d} \psi \partial_{\xi} u=\overline{\partial_{\xi} u}$.

This, moreover, results in

$\overline{\zeta \frac{\partial u}{\partial \xi}+u \frac{\partial \zeta}{\partial \xi}}=\iint \frac{\partial}{\partial \xi}(u \zeta) \mathrm{d} z \mathrm{~d} \psi \approx \frac{\partial}{\partial \xi} \iint(u \zeta) \mathrm{d} z \mathrm{~d} \psi$

$\approx \frac{\partial}{\partial \xi} \bar{u} \iint \zeta \mathrm{d} z \mathrm{~d} \psi=\bar{u} \frac{\partial \bar{\zeta}}{\partial \xi}+\bar{\zeta} \frac{\partial \bar{u}}{\partial \xi}$

since $u$ is less variable than $\zeta$. All of this leads to the crossaveraged vorticity equation in the steady case

$\bar{u} \frac{\partial}{\partial \xi} \bar{\zeta}+(f+\bar{\zeta}) \overline{\operatorname{div} \boldsymbol{u}} \approx \overline{\frac{1}{\rho}(\operatorname{curl} \boldsymbol{F})_{z}}=-\mathrm{X} \bar{\zeta}$

and thus to the corresponding solution, Eq. (10), in the main text for $\bar{\zeta} \ll f$.

Similarly, the mass conservation equation

$u \frac{\partial}{\partial \xi} h+h \operatorname{div} \boldsymbol{u} \approx E\left|u-u_{2}\right|$

becomes Eq. (11) in the main text.

\section{Appendix B: The spline interpolation of the $u_{i}$ and $h_{\mathrm{i}}$}

To use the cross-averaged Eastern Mediterranean Deep Water (EMDW) data of A01 (Tables 1 and 2), we computed a continuous $u(\xi)$ and $h(\xi)$ spline interpolation of the $u_{i}$ and $h_{i}$ from transect $i=1,2, \ldots$ (Fig. 6). This problem may be solved exactly by fitting a polynomial of degree $n-1$. Unfortunately, for such a "polynomial" solution, it is not easy to control for the influence of any particular observation. Moreover, it can behave very strangely at the boundaries.

Spline interpolation achieves a better result. In order to enhance the spline flexibility around the sill, following Durbin and Koopman (2001) we introduce a scale parameter $\sigma$ that varies as $\sigma^{2}=v^{2}+\mu \Lambda(\xi)$ with $\mu \gg v^{2}$. For such a "modified" spline interpolation, one has

$\Lambda(\xi)=\frac{35}{32}\left[1-\left(\frac{2\left(\xi-\Delta \xi_{m}\right)}{\xi_{m}-\xi_{m-1}}\right)^{2}\right]^{3}$,

where $\Delta \xi_{m}=\left(\xi_{m}-\xi_{m-1}\right) / 2$,

for all points in an interval $\xi_{m-1}<\xi<\xi_{m+1}$ and zero elsewhere. We moreover impose that our transect $\mathrm{V}$ is a local minimum for $h(\xi)$ and a maximum of $u(\xi)$ as shown in Fig. 6. Note that, although these last plots might look rather discontinuous over the sill, in reality this apparent effect is due to the vigorous evolution of the current over the sill. Moreover, we compare such a modified spline interpolation of $u_{i}$ with monthly averaged data of PROTHEUS (see text). Along-channel velocities for January 1997 and April 1998 cruises are shown in Fig. 5, superimposed on modified spline interpolations of both MATER II and MATER IV.

Author contributions. E. Salusti developed the analytic theory with contributions of F. Falcini, who also performed the vorticity and PV diagnosis. Both authors prepared the manuscript.

Acknowledgements. We thank M. Astraldi and G. P. Gasparini for help and criticism, and V. Rupolo and G. M. Sannino for the PROTHEUS data. Many thanks are also due to M. Kurgansky, L. Pratt, and R. Wood for suggestions about potential vorticity dynamics, as well as to T. Proietti for discussion regarding the spline interpolations. This work has been funded by the RITMARE Italian Research Ministry (MIUR) Projects.

Edited by: M. Hecht

\section{References}

Armi, L. and Farmer, D.: The internal hydraulics of the Strait of Gibraltar and associated sills and narrows, Oceanol. Acta, 8, 3746, 1985.

Astraldi, M., Gasparini, G. P., Gervasio, L., and Salusti, E.: Dense water dynamics along the Strait of Sicily (Mediterranean Sea), J. Phys. Oceanogr., 31, 3457-3475, 2001.

Baringer, M. O. N. and Price, J. F.: Mixing and spreading of the Mediterranean outflow, J. Phys. Oceanogr., 27, 1654-1677, 1997a.

Baringer, M. O. N. and Price, J. F.: Momentum and energy balance of the Mediterranean outflow, J. Phys. Oceanogr., 27, 16781692, $1997 \mathrm{~b}$.

Borenäs, K. and Lundberg, P.: Rotating hydraulics of flow in a parabolic channel, J. Fluid Mech., 167, 309-326, 1986.

Borenäs, K. M. and Lundberg, P. A.: On the deep-water flow through the Faroe Bank Channel, J. Geophys. Res.-Oceans, 93, 1281-1292, 1988. 
Bryden, H. L. and Kinder, T. H.: Steady two-layer exchange through the Strait of Gibraltar, Deep Sea Res. Pt. I, 38, S445-S463, 1991.

Chen, C., Beardsley, R. C., and Limeburner, R.: The structure of the Kuroshio southwest of Kyushu: velocity, transport and potential vorticity fields, Deep Sea Res. Pt. I, 39, 245-268, 1992.

Durbin, J. and Koopman, S. J.: Time Series Analysis by State Space Methods, Oxford University Press, Oxford, UK, 2012.

Ellison, T. H. and Turner, J. S.: Turbulent entrainment in stratified flows, J. Fluid Mech., 6, 423-448, 1959.

Gerdes, F., Garrett, C., and Farmer, D.: On internal hydraulics with entrainment, J. Phys. Oceanogr., 32, 1106-1111, 2002.

Gill, A. E.: The hydraulics of rotating-channel flow, J. Fluid Mech., 80, 641-671, 1977.

Gill, A. E.: Atmosphere-Ocean Dynamics, vol. 30, Academic Press, San Diego, USA, 662 pp., 1982.

Hogg, N. G.: Hydraulic control and flow separation in a multilayered fluid with applications to the Vema Channel, J. Phys. Oceanogr., 13, 695-708, 1983.

Holton. J. R.: Introduction to Dynamic Meteorology, Academic Press, New York, USA, 319 pp., 1972.

Jain, S. C.: Open-Channel Flows, John Wiley and Sons, New York, USA, 328 pp., 2001.

Johnson, D. A., McDowell, S. E., Sullivan, L. G., and Biscaye, P. E.: Abyssal hydrography, nephelometry, currents, and benthic boundary layer structure in the Vema Channel, J. Geophys. Res., 81, 5771-5786, 1976.

Johnson, G. C. and Ohlsen, D. R.: Frictionally modified rotating hydraulic channel exchange and ocean outflows, J. Phys. Oceanogr., 24, 66-78, 1994.

Killworth, P. D.: Mixing of the Weddell Sea continental slope, Deep Sea Res., 24, 427-448, 1977.

Killworth, P. D.: Flow properties in rotating, stratified hydraulics, J. Phys. Oceanogr., 22, 997-1017, 1992.

Lacombe, H. and Richez, C.: The regime of the Strait of Gibraltar. In: J.C.J. Nihoul (Editor), Hydrodynamics of Semi-Enclosed Seas, Elsevier Oceanography Series 34, Elsevier, Amsterdam, 13-73, 1982.
Paldor, N.: Stability and stable modes of coastal fronts, Geophys. Astro. Fluid, 27, 217-228, 1983.

Pratt, L. J., Helfrich, K. R., and Leen, D.: On the stability of ocean overflows, J. Fluid Mech., 602, 241-266, 2008.

Pratt, L. L. and Whitehead, J. A.: Rotating Hydraulics: Nonlinear Topographic Effects in the Ocean and Atmosphere, vol. 36, Springer, New York, USA, 2007.

Salon, S., Crise, A., and Van Loon, A. J.: Dynamics of the bottom boundary layer, contourites, Developments in Sedimentology, 60, 83-98, 2008.

Sannino, G., Herrmann, M., Carillo, A., Rupolo, V., Ruggiero, V., Artale, V., and Heimbach, P.: An eddy-permitting model of the Mediterranean Sea with a two-way grid refinement at the Strait of Gibraltar, Ocean Model., 30, 56-72, 2009.

Smith, P. C.: A streamtube model for bottom boundary currents in the ocean, Deep-Sea Res., 22, 853-873, 1975.

Sparnocchia, S., Gasparini, G. P., Astraldi, M., Borghini, M., and Pistek, P.: Dynamics and mixing of the Eastern Mediterranean outflow in the Tyrrhenian basin, J. Marine Syst., 20, 301-317, 1999.

Stansfield, K., Smeed, D. A., Gasparini, G. P., McPhail, S., Millard, N., Stevenson, P., Webb, A., Vetrano, A., and Rabe, B.: Deep-sea, high-resolution, hydrography and current measurements using an autonomous underwater vehicle: the overflow from the Strait of Sicily, Geophys. Res. Lett., 28, 2645-2648, 2001.

Turner, J. S.: Turbulent entrainment: the development of the entrainment assumption, and its application to geophysical flows, J. Fluid Mech., 173, 431-471, 1986.

Whitehead, J. A.: Topographic control of oceanic flows in deep passages and straits, Rev. Geophys., 36, 423-440, 1998.

Whitehead, J. A., Leetmaa, A., and Knox, R. A.: Rotating hydraulics of strait and sill flows, Geophys. Astro. Fluid, 6, 101$125,1974$.

Wood, R. and McIntyre, M.: A general theorem on angular momentum changes due to potential vorticity mixing and on potential energy changes due to buoyancy mixing, J. Atmos. Sci., 67, 1261-1274, 2010. 